\title{
THE AMBON OF SANT'ANDREA IN PISTOIA: A COMPARISON BETWEEN LASER SCANNER AND PHOTOGRAMMETRIC DIGITIZATION OF MARBLE SURFACES
}

\author{
A. Conti, L. Fiorini, G. Tucci
}

\begin{abstract}
GeCO Lab, Dept. of Civil and Environmental Engineering, University of Florence, Via di Santa Marta 3, Firenze, Italia,
\end{abstract} (alessandro.conti, lidia.fiorini, grazia.tucci)@unifi.it

\section{Commission II}

KEY WORDS: Laser scanner, Structure-from-Motion, Marble, Comparison, Ambon.

\begin{abstract}
:
The ambon by Giovanni Pisano in the church of Sant'Andrea in Pistoia (Italy) consists of a hexagonal platform raised on slender columns standing on bases and sculptures with different heights. In the 17th century, it was disassembled and placed in a different location and, also for this reason, is currently in an endangered condition. As part of a multi-disciplinary programme of investigations and monitoring, a 3D survey was requested. The challenging aspect of the survey is related with the material of the work of art, as it is completely made of different kinds of white and red marbles. These materials are translucent and light diffuses through them, so the laser beam scatters beyond the surface and biases measurements in an unpredictable way. Tests were carried out, comparing two scanners with different characteristics and digital photogrammetry. The results show significant differences between the three technologies, identify the best solution in relation to the desired objectives, and highlight how different acquisition techniques affect the suitability of models for subsequent applications.
\end{abstract}

\section{INTRODUCTION AND AIM}

Currently, digital documentation of cultural heritage is mainly based on laser scanning and digital photogrammetry techniques for producing detailed, accurate, and realistic 3D models. In conservation, digitally acquired geometries and colours are used to record materials, state of conservation and building techniques, and to model "digital twins" that simulate the behaviour of the real object (Tucci et al, 2017, Santos et al., 2017, Fazio and Lo Brutto, 2021).

The paper reports the digitisation project of the ambon of the Sant'Andrea church in Pistoia. Considering that the work of art is made of a challenging material like marble, tests have been carried out for evaluating the performances of different technologies and devices. The aim of the paper is to help identify the best techniques for digitising such works, and to highlight how the result is influenced by the adopted technology.

\section{THE CASE STUDY}

\subsection{Description}

The ambon in the Sant'Andrea church in Pistoia is considered the masterpiece of Giovanni Pisano and one of the most important Italian sculptural works (Siedel, 2012). In medieval churches, the ambon was a raised architectural structure for reading the Gospel.

The church was built in the Romanesque style in the 12th century with massive walls. Its dimly lit interior is divided into three narrow naves, giving a characteristic vertical soaring, and ends with an apse surmounted by single-lancet windows.

The ambon was built to a hexagonal ground plan (Dent, 2008), with an elevation divided into three tiers:

- bases and columns,

- $\quad$ arches and spandrels,

- parapet.
The sides of the hexagon are about $1.4 \mathrm{~m}$, the overall height is $3.95 \mathrm{~m}$, and the platform is $3 \mathrm{~m}$ above the ground.

The platform is supported by seven slender columns (six at the corners and one in the centre. Columns have two lengths and different Corinthian capitals, three stand on bases and four on animal- or human-shaped sculptures, as in other examples in Pistoia and the ones by Nicola Pisano (Giovanni's father) in Pisa and Siena.

The upper architectural elements and the parapets are carved in high relief and depict scenes from the life of Christ, religious symbols, the Sibyls and Prophets (Figure 1).

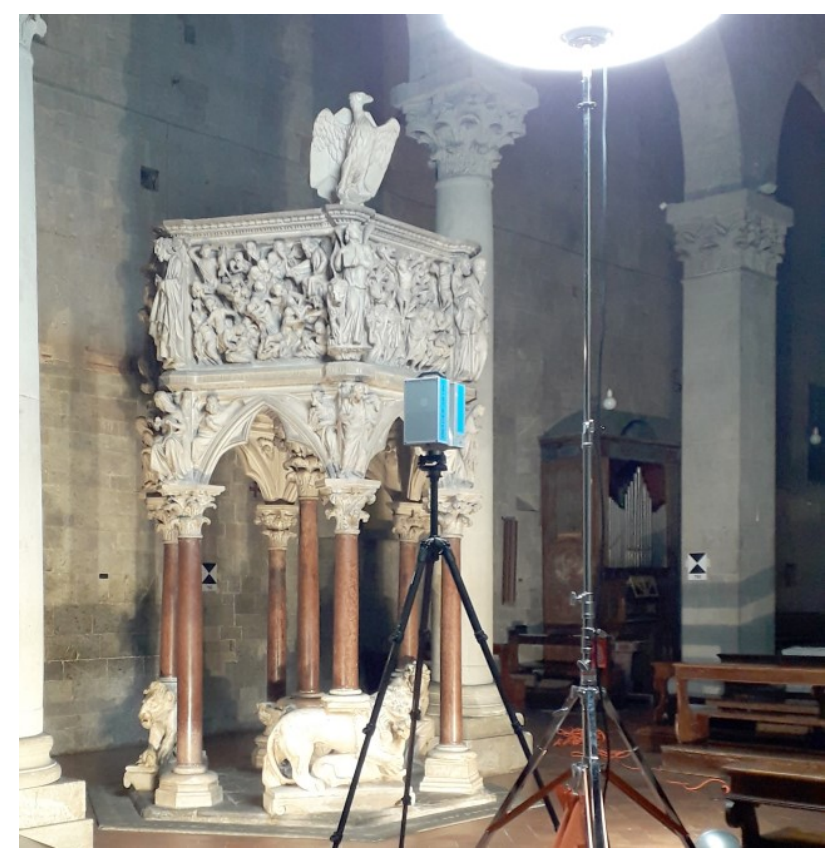

Figure 1. The ambon during the survey. 


\subsection{Original layout and relocation}

The ambon was made between 1298 and 1301 and originally was situated on the right side of the altar. After the CounterReformation, ambons became obsolete and were often demolished, but because of its artistic value, this work was dismantled and rebuilt in the fifth space between the columns that separate the main nave and the South one (Carli, 1986), but the parts were reassembled in a different order. For the reconstruction of its original appearance, two slightly different proposals have been made (Jászai, 1968; Mellini, 1969), but they had different fortunes in critical circles (Gnudi, 1972). Also for this reason, the work of art deemed to be endangered and monitored, as its columns are visibly inclined, causing stresses in the structure. These irregularities were compensated for by filling the spaces between columns and adjacent elements with lead and aggregate flakes.

\subsection{Previous and current preservation campaigns}

Because of its artistic importance and apparent unstable condition, the conservation of this work of art has been considered worthy of the utmost care for two centuries. Aldovrandi et al. (2011) presents the multidisciplinary investigations started in 2007, including a laser scanner survey. The paper does not mention the issues related to marble scanning, however, only 2D images and elaborations of the point cloud are reported and the original digital data are not available for comparisons.

From that study, a new research campaign has started to improve knowledge of the dynamic behaviour of the pulpit and to deepen the relationships with the soil, which in recent years has been increasingly influenced by the alterations induced by climate change (Huerto-Cardenas et al., 2021).

In this still ongoing research, a 3D survey was requested to obtain models for:

- the structural analysis,

- documenting the decay,

- referencing the results of the investigations,

- supporting the communication project during the restoration.

The object has the dimensions of a small architecture, but the sculpted figures have very small details. This required to accurately document both the overall volumetry and layout, and the details of the architectural parts (like capitals and mouldings) and of the carved bas-reliefs with small protruding figures. Bartoli et al. (2020) reports first results of the ongoing investigations and stresses that the reliability of the numerical model is affected by the simplification of the geometric model. For this reason, it was decided to investigate how the accuracy of measurements is affected by data acquisition techniques in a concrete case.

\section{OPEN ISSUES IN 3D DOCUMENTATION OF SCULPTURES}

\subsection{Digitisation techniques: pros and cons}

The currently predominant techniques for the 3D documentation of such works of art are structured light scanning, laser scanning (both using triangulation and terrestrial scanners) and Structure from Motion (SfM) photogrammetry. All of them show benefits and drawbacks (Remondino, 2011, Georgopulos et al., 2017, Bonora et al., 2021a).

The main advantage of scanning techniques is the speed of acquisition. Among them, triangulation scanners, both structured light (TSL) and laser (TL), consist of an emitting device and a sensor at a defined distance (baseline). A point on the object is measurable only if it is simultaneously visible from both sides. In this case study, even with a smaller handheld scanner, many gaps would result, because of the complex shape with overlapping parts and deep concavities.

On the other hand, terrestrial scanners, both using time-of-flight (TOF) and phase shift (PS) techniques, measure a point from a single position, as long as is in the line of sight. Gaps could be reduced doing scans from more different positions, but terrestrial scanners are quite bulky and must stand still for a longer time. Moreover, often the scanner cannot be placed in the best positions because of the geometry of the object and its location.

Using SfM photogrammetry, it is possible to sample a surface using photographs adequately taken from an appropriate number of viewpoints. As an off-the-shelf camera is requested, $\mathrm{SfM}$ is a very flexible system, but a good illumination is necessary and processing needs more steps and time. Furthermore, for scaling and referencing the model, the 3D coordinates of a suitable number of control points are needed, usually measured with a topographic technique, as total station or GNSS (Mojano et al., 2020, Adamopulos et al., 2021).

\subsection{Marble, a challenging material}

In this case study, the main issue is that the ambon is entirely made of different types of white and red marbles. All current acquisition techniques efficiently record opaque surfaces with lambertian reflectance, but light is scattered out beyond the actual surface in translucent materials with a low refractive index. This effect gives marbles the characteristic waxy look appreciated by sculptors, but, on the other hand, produces a significant bias in range measurements based on the reflected electromagnetic radiation.

This problem has been highlighted by scholars since the first applications of scanners to cultural heritage.

Godin et al. (2001) asserted that subsurface scattering causes noise and measurement bias, but it is negligible in weathered and carved marbles. On the other hand, Tsakiri et al. (2003) observed this effect on an ancient sculpture scanned with a Minolta VI-900 TSL. Voetgle and Wakaluk (2009) systematically scanned samples of various building materials with a PS scanner (Leica HDS 6000) by modifying distances, incidence angles, reflectivity, ambient lighting, and wetness. They argued that materials influence significatively range measurements and no constant correction value could be found. Guidi et al. (2009) tested two triangulation scanners (a TSL and a TL) and a TOF scanner on flat samples of different marbles. TOF scanner gave the greater penetration effect, but authors also underline the different behaviour on various marbles. Callieri et al. (2009) tried to reduce measurement error of scans of a marble statue done with a TOF scanner by filtering range measurements during postprocessing. El-Hakim et al. (2009) reported up to $5 \mathrm{~mm}$ error on weathered and dirty marble sampled with a TOF scanner. Garcia-Fernandez (2016) compared data acquired with two scanners (a Faro Focus PS and a Leica Scanstation C10 TOF), evaluating how the incidence angle affects the results. For the massive documentation of sculptures of the Uffizi Project, Malik and Guidi (2018) scale the SfM surveys on laser scans, neglecting the dimensional error due to subsurface scattering. Angheluță and Rădvan (2020) compare TL and SfM for acquiring small sculptures made with translucent materials (wax and jade), reporting differences up to $4 \mathrm{~mm}$.

In summary, results are inconclusive and sometimes contradictory, due to the large number of parameters involved, 
like the properties of materials (colour, anisotropy, translucency, refraction index, etc.), the characteristics of devices (laser frequency, beam intensity, laser spot size, echoreception threshold, etc.) and the reciprocal position between device and object (distance, angle of incidence, etc.).

No scanning system appears to be completely free of this problem. Furthermore, to limit the variables, most studies have been carried out in the laboratory on flat samples. Problems encountered in real cases, such as the effect on marbles with different ageing and finish, or the summation of errors when a three-dimensional object is scanned from several points of view, have been understudied.

\section{THE SURVEY WORKFLOW}

\subsection{Overall survey planning}

In concrete cases, most of the above-mentioned parameters cannot be modified, so, from the outset, the digitisation of the ambon was a technological challenge due to the material and morphological characteristics of this work of art.

Using commercial tools, the only parameter that can be selected is the technology (scanning or photogrammetry) and, if possible, is better to test different solutions and devices. For this reason, acquisitions have been carried out with two scanners and SfM photogrammetry. Results are presented in Section 5.

\subsection{Location}

The location of the pulpit, the geometry of the surrounding spaces, the poor lighting, and working in a church used both for worship and as a tourist site were the critical issues that affected the fieldwork.

The ambon, in its current configuration between the nave and the south aisle, is so close to a column that the edge supported by the human statue almost touches it. Similarly, the side aisle is very narrow and there is little space between the object and the wall. Therefore, the available space around the ambon is variable and sensors cannot be freely placed in the most appropriate positions, regardless of adopted technique.

Also the space under the work of art is small; the central column, the sculptures supporting the columns, and the capitals hinder equidistant and regular acquisitions. The inside of the parapets and the floor were surveyed by placing only the scanners on the platform, to avoid overloading or damaging a vulnerable structure. Although the pulpit is relatively low, acquisitions from ground level only could leave some unsampled surfaces. So, images for SfM were done also on a mobile scaffold, or a ladder in smaller places.

As mentioned, the church is rather dark and has a temporary, nonadjustable, paid-for lighting system that illuminates the entire church. Therefore, an Airstar lighting balloon was used. It is autonomous, transportable, and provides diffuse light with a known colour temperature, however it is bulky, so it was not always possible to place it in the most appropriate position.

\subsection{Topographic network}

As known (Bonora et al., 2021b), a well-done topographic network is a valid tool that allows to i) define a single reference system for multi-sensor acquisitions, ii) reduce potential misalignment between scans and drift, iii) scale and control a photogrammetric model, iv) monitor a structure repeating measurements over time. In this case, a topographic network measured with a total station was designed and permanently set. The coordinates of the network vertices were defined with overdetermined geometric schemes and Least Squares adjustment. Eight A4 size targets were placed and measured on walls around the ambon for aligning and referencing the scans and more than 300 small targets $(1 \times 1 \mathrm{~cm})$ were placed directly on the object for the photogrammetric survey.

\subsection{Laser scanner acquisitions and processing}

In order to compare the results, the survey was carried out separately with two terrestrial laser scanners. Most significant differences are listed in Table 1

\begin{tabular}{|l|l|l|l|}
\hline & Model & Technology & Laser wavelength \\
\hline $\mathbf{1}$ & Z+F 5010C & Phase-shift & $1500 \mathrm{~nm}$ (near infrared) \\
$\mathbf{2}$ & Leica C10 & Time-of-flight & $532 \mathrm{~nm}$ (green) \\
\hline
\end{tabular}

Table 1. Main features of the two laser scanners.

With both devices, scans were made with a resolution of $6 \mathrm{~mm}$ at $10 \mathrm{~m}$, also including the acquisition of the RGB value.

In both cases 30 scans were taken. If possible, scans were made for each side and corner of the hexagon at about two metres, however in some cases the surrounding columns and walls are very close, so the distance was shorter. From each position, two scans were made at different heights to reduce the gaps, as the figures of the bas-reliefs are very protruding.

Three more scans were made between the columns below the platform, two above it, and two further away to locate the pulpit in the context of the building.

The same acquisition pattern was repeated with both devices, but unfortunately it was not possible to scan from the same exact position, since scanners were not available at the same time.

For both surveys, the scans were then aligned and referenced using targets and further optimised by a global registration based on the ICP algorithm, resulting in two distinct point models in the same reference system.

\subsection{SfM photogrammetry}

The design of a photogrammetric survey is a challenging task but, in some cases, such as in aerial or UAV photogrammetry, it can benefit from defined guidelines. On the other hand, the photogrammetric survey of an object with a very complex threedimensional shape, aimed at obtaining a high-resolution 3D model, requires a careful design that must also consider the management of a larger than usual number of data, i.e. images, ground control points (GCPs) and check points (CPs). (Table 2).

\begin{tabular}{|l|l|l|l|}
\hline & Images & GCPs & CPs \\
\hline Block A & & & \\
\hline $\begin{array}{l}\text { Upper level } \\
\text { Middle level }\end{array}$ & $\begin{array}{l}2881 \\
1599 \\
\text { Capitals }\end{array}$ & \multirow{3}{}{$\begin{array}{l}\text { 635 } 194 \\
\text { Block B }\end{array}$} & $\boldsymbol{\}} 51$ \\
\hline Lower level & 1414 & 42 & \\
\hline Total & $\mathbf{6 5 2 9}$ & $\mathbf{2 3 6}$ & $\mathbf{6 8}$ \\
\hline
\end{tabular}

Table 2. Images and control points.

So many targets were laid out, to ensure a suitable number of points on each figure and parapet panel, so that they could be separately processed. Instead, it was later preferred to divide them into two blocks A and B only (Figure 2).

In SfM photogrammetry a standard camera is used, which is lightweight and easy to handle even on a scaffolding, but, even more than with laser scanning, the device must be placed in many different viewpoints to get a complete, good-quality 3D model (Ruiz et al., 2021). 
A Nikon D700 camera and a $50 \mathrm{~mm}$ prime lens were used. Considering that the camera has a Pixel size $=0.008459 \mathrm{~mm}$ and an average distance of $1 \mathrm{~m}$ from the object, the well-known formula

$$
\text { GSD = Distance } x \text { Pixel size / Focal length }
$$

indicates a $\mathrm{GSD}=0.2 \mathrm{~mm}$, appropriate to the defined goals. For each side of the parapet, several parallel strips were made, according to regular acquisition patterns, either with the optical axis perpendicular to the mean surface or inclined to both sides, in order to best record undercuts.

Then, a series of converging photos were made on the characters animating the panels, as well as on the corner figures, column bases and capitals.

Despite the use of the lighting balloon, the illumination was barely adequate, so it was imperative to optimise the balance of the exposure triangle parameters (Luhmann et al., 2019). The shutter speed had to be high, because the photos on the scaffold were taken by hand, and the ISO sensitivity had to be low to reduce image noise. So, the exposure was the result of a compromise, the aperture (and thus the depth of field) was not always sufficient, especially in inclined photos.

Glares were an additional problem of the photogrammetric acquisition. White marble parts have an aged surface, so, it was possible to prevent most reflections with appropriate lighting. On the other hand, the columns are dark but shiny, so some glare and strong contrasts occurred in the images even using polarising filters.

Due to the large number of images, the project was processed in two separate blocks A) upper level, middle level, and capitals, B) lower level (cfr. Table 2 and Figure 2).

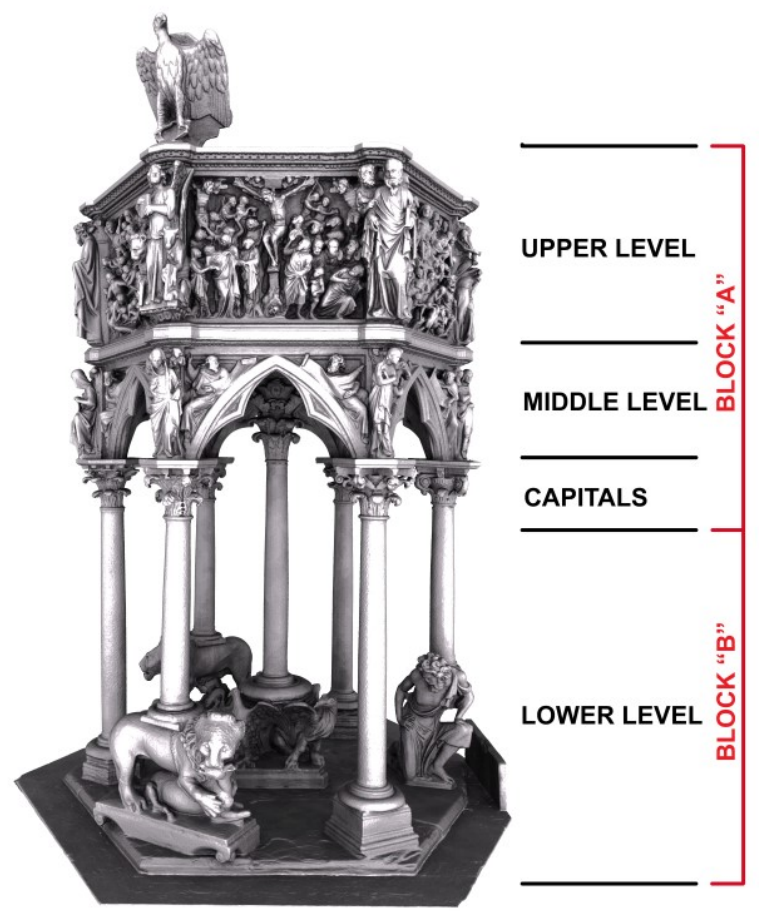

Figure 2. Subdivision of the work in blocks and levels (on the C10 mesh model).

SfM projects were processed with Agisoft Metashape Pro software, obtaining an average error on control points and check points lower than $0.003 \mathrm{~m}$.

The visual quality of the models is also good, with a fine colour fidelity. In mesh models some regions were slightly noisy in areas with insufficient depth of field (Nicolae et al., 2014).

\section{RESULTS}

In compliance with literature, all point clouds are affected by considerable noise (Figure 3 ).

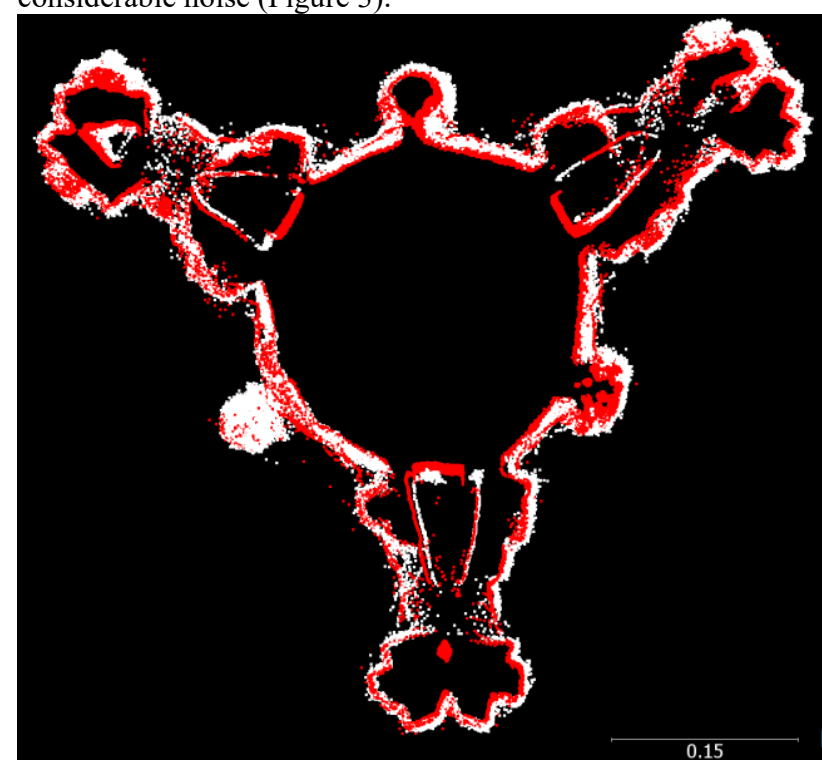

Figure 3: Section of point clouds of a capital, acquired with Z+F 5010C and Leica C10.

In laser scanner surveys, the scattering of the laser beam beyond the actual surface biases the result. It should be noted that the collection of scans has more noise than just one, as points acquired from several positions, each with a different bias, are added together.

Comparing the meshes, this becomes even more evident, as the thinner protruding parts of the sculptures appear eroded by the combined effect of the laser penetration into the marble from several directions (Figure 4).

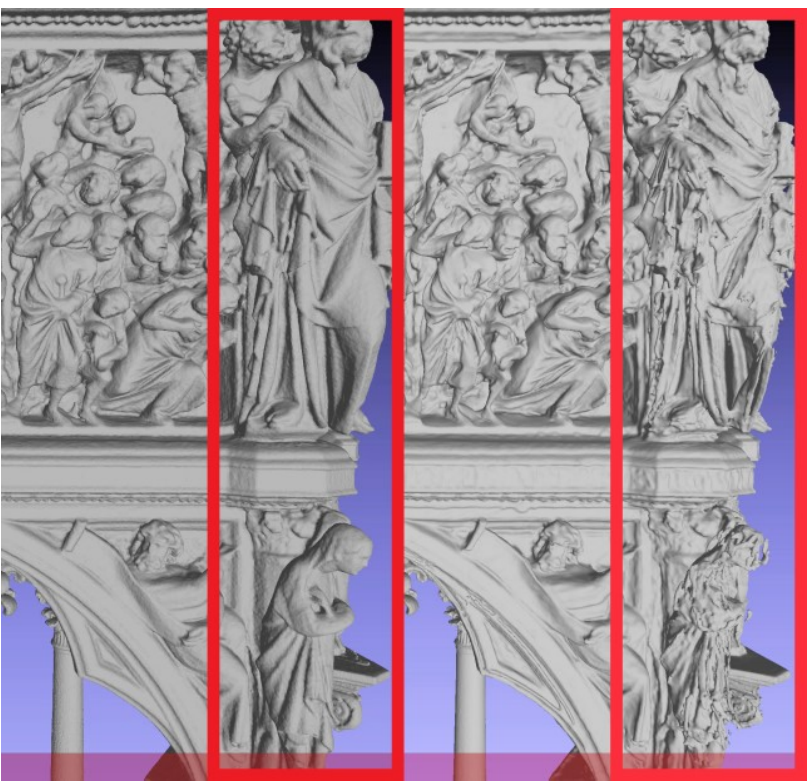

Figure 4: Meshes from data acquired with $\mathrm{Z}+\mathrm{F}$ 5010C (left) and Leica C10 (right).

Although no point cloud can be completely free of this effect, data acquired with different techniques and instruments were compared to assess the differences.

Two significant parts of Block A have been chosen; the side including the Crucifixion (A-1) and a flat part of the entrance 
jamb (A-2). Test B has been done on a part of a column (Figure $5)$.

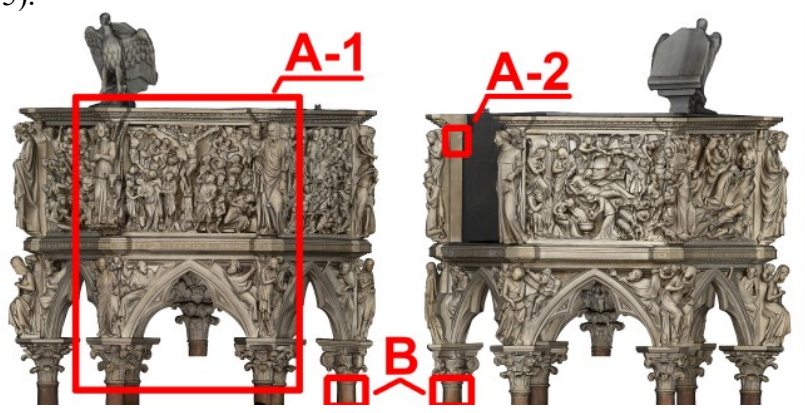

Figure 5. Scheme of the tested areas.

All comparisons were made with the $\mathrm{M} 3 \mathrm{C} 2$ plugin (Lague et al., 2013) implemented in Cloud Compare (Cloud Compare development team, 2022). Data are coded as follows:

\begin{tabular}{|l|l|l|}
\hline Code & Technique & Device \\
\hline SfM & SfM photogrammetry & \\
C10 & Laser Scanning & Leica Scanstation C10 \\
ZF & Laser Scanning & Z+F 2010C \\
\hline
\end{tabular}

Table 3. Codes given to the acquisitions.

\subsection{A-1 The Crucifixion}

This part was chosen because it is large and includes several marble parts (presumably with slightly different characteristics) and a variety of carved, smooth, and protruding surfaces. The survey of this side was relatively simple, because it has the largest space in front.

Figures 6,7 , and 8 show the comparisons between point clouds in the range $-0.02 /+0.01 \mathrm{~m}$ and their histograms.
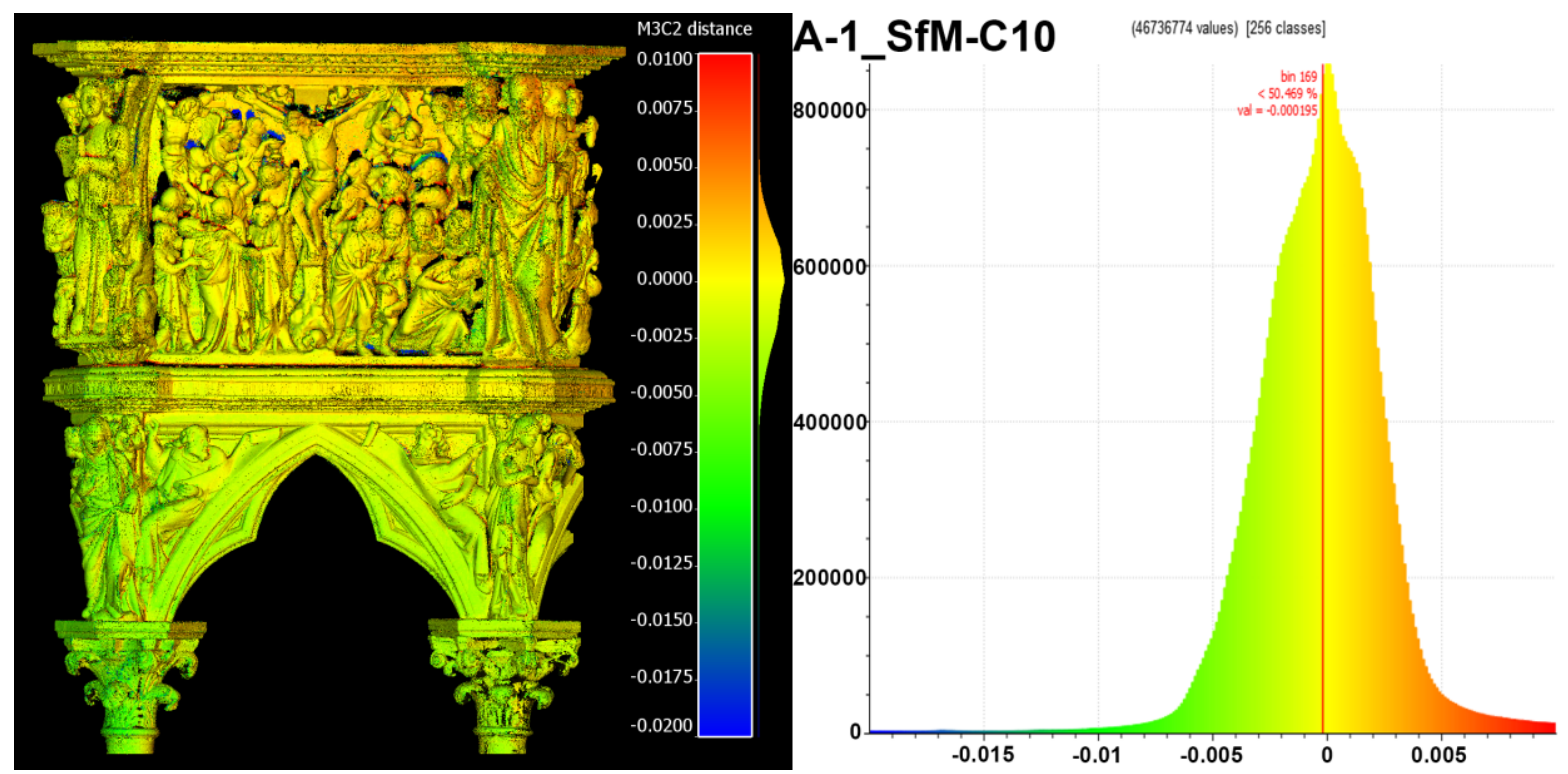

Figure 6. SfM - C10 comparison and histogram.
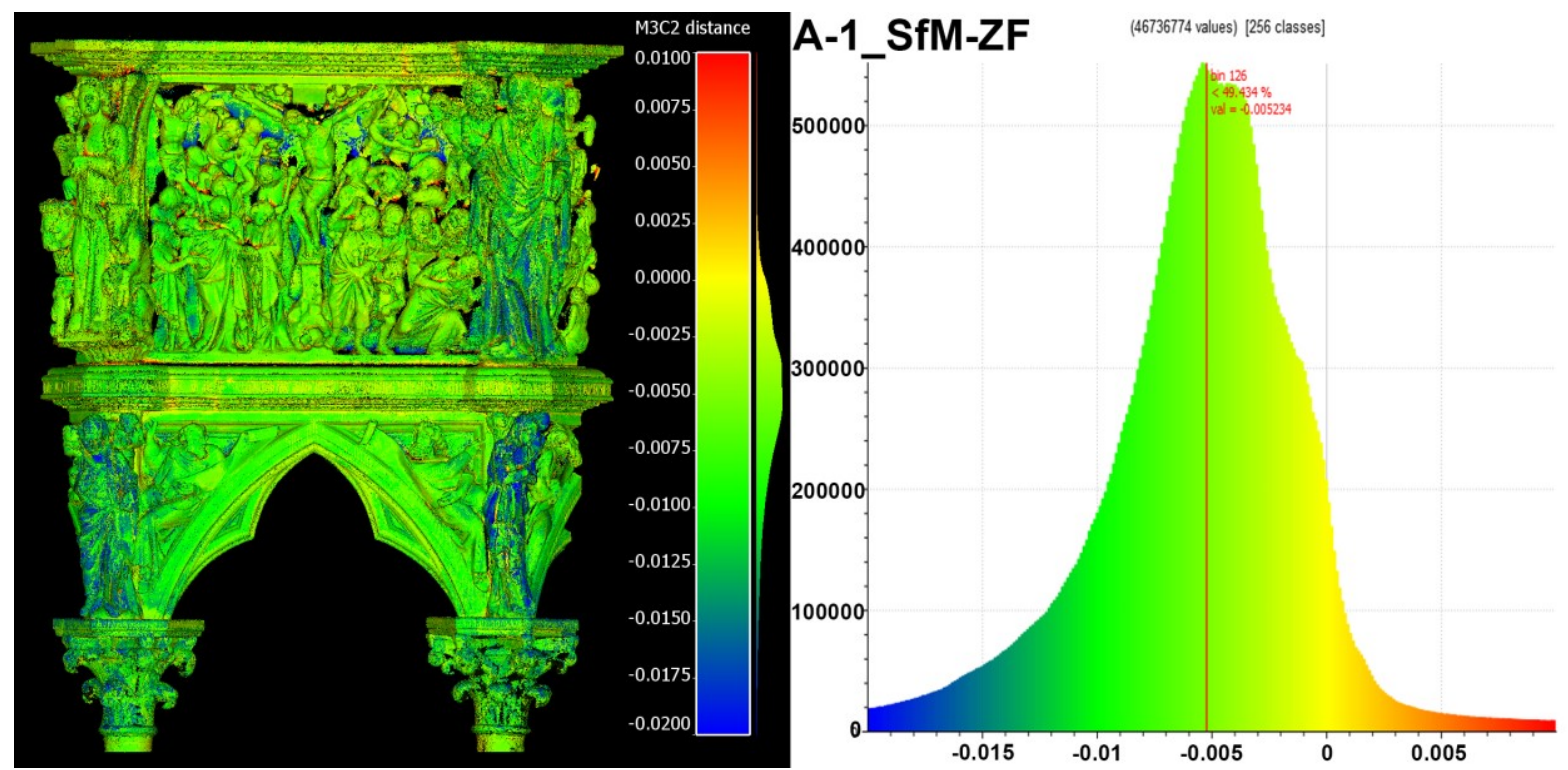

Figure 7. SfM - ZF comparison and histogram. 

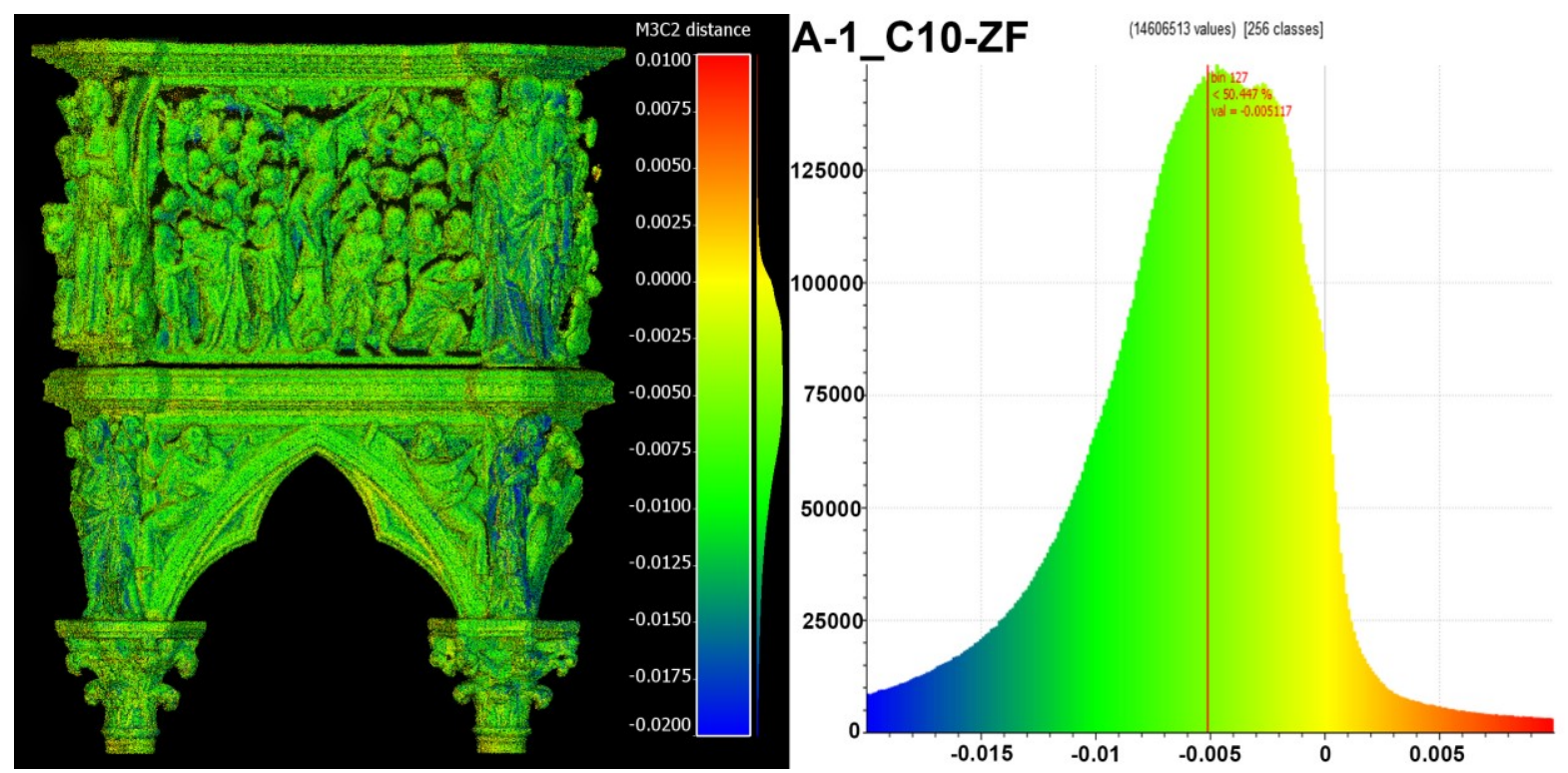

Figure 8. C10 - ZF comparison and histogram.

Considering that the comparisons have non-normal distributions, the median of the distance between SfM and C10 is of $0.0002 \mathrm{~m}$ (Figure 6).

On the other hand, the average difference between SfM and ZF exceeds $0.005 \mathrm{~m}$ (Figure 7). The changes in the gradient of the histogram are probably caused by the combination of unequal errors associated with the above-mentioned parameters. In most protruding parts (such as the figures on the sides and the capitals) the distance between the point clouds exceeds $0.02 \mathrm{~m}$, and this could be due to the combination of data from many directions.

The comparison between $\mathrm{C} 10$ and ZF shows a median around $0.005 \mathrm{~m}$. The wider curve is related with the higher noise of both point clouds (Figure 8).

\subsection{A-2 Entrance jamb}

A relatively large flat part $(85 \times 85 \mathrm{~mm})$, scanned by several positions but not from opposite sides, was chosen for the second test (Figure 9).

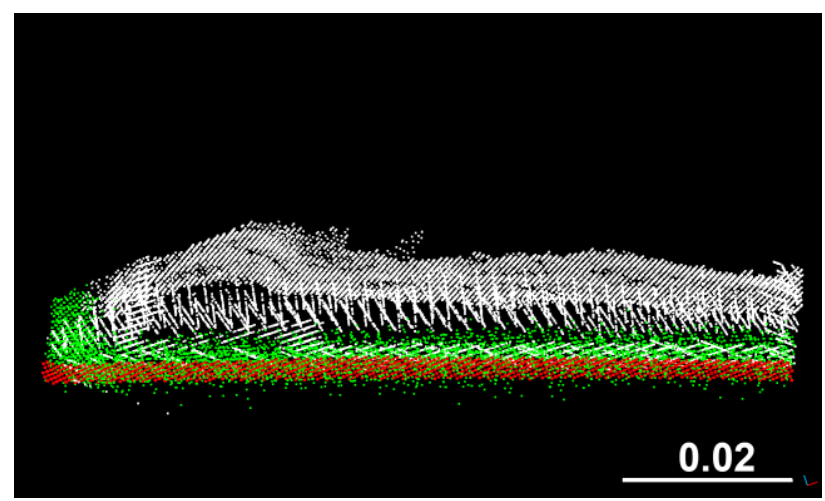

Figure 9. Slice of the point clouds in A-2 test area, showing different noise and shift. SfM in red, C10 in green, ZF in white.

The comparisons show slightly greater distances than in A-1; in the one between SfM and $\mathrm{C} 10$ the median distance is $0.001 \mathrm{~m}$, in the other between SfM and ZF it is $0.008 \mathrm{~m}$ (Figure 10).
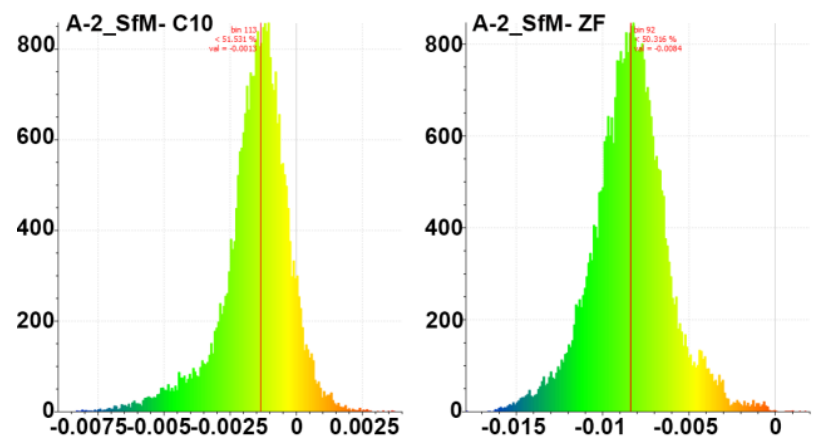

Figure 10. A-2. Histograms of the comparison between SfM and $\mathrm{C} 10$ (left) and SfM and ZF (right).

\subsection{B Column}

The acquisition of the column, made from another marble, gave completely different results. The distance between the point clouds is always smaller than $0.001 \mathrm{~m}$. However, the large dispersion indicates high noise in all data, probably also related on one hand to the dark colour, on the other to the laser wavelength in the scanners (Figure 11).
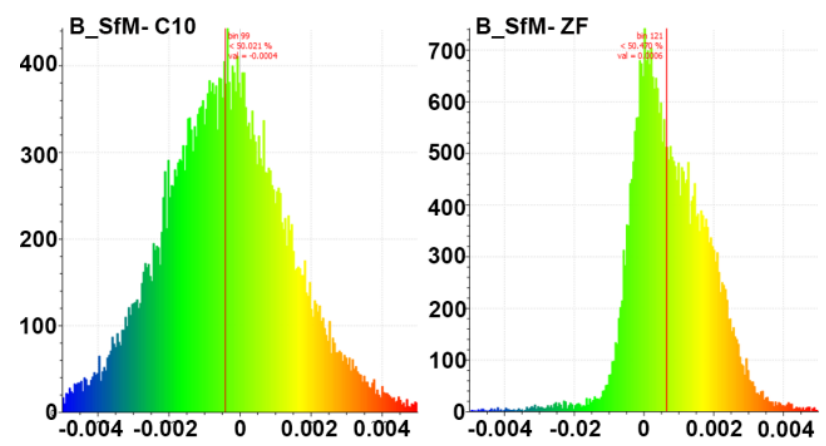

Figure 11. B. Histograms of the comparison between SfM and C10 (left) and SfM and ZF (right). 


\section{CONCLUSIONS}

The tests showed significant differences between the point clouds obtained by SfM photogrammetry and laser scanning. Considering the SfM survey as ground truth, on white marble the subsurface scattering effect was much higher in the survey performed with the $\mathrm{Z}+\mathrm{F} 5010 \mathrm{C}$ scanner $(5 \mathrm{~mm})$, while it was almost absent in the one done with Leica Scanstation C10. The marble of the columns, however, gave different results, confirming the impossibility of defining a constant correction value. Furthermore, it was pointed out that the details can be illegible in a cloud generated by several scans.

This helps in choosing the best surveying technique for marble works. It should be noted that the bias is approximately constant, so it has a greater impact on smaller works, such as tiny sculptures and objects.

Applications related to the conservation of cultural heritage generally require a high level of detail, even when the model is used only for visualisation. It is therefore better to use photogrammetry or a scanner with a low subsurface scattering effect, which gives similar accuracy with less fieldwork and processing time.

For some structural modelling applications, a model with a low level of detail is also considered acceptable, as this will need to be further simplified. However, the incidence of this error must be considered.

The surface of Block A (computed on the SfM mesh model) is approximately $49.3 \mathrm{~m}^{2}$ and the volume is $1.70 \mathrm{~m}^{3}$. As the average shift of the point cloud of the ZF model is $-0.005 \mathrm{~m}$, by subtracting this thickness from the total surface area, the resulting volume could be up to $0.25 \mathrm{~m}^{3}$ less than the real one, leading to a potential underestimation up to $14.7 \%$ of the selfweight.

The relationship between laser beam wavelength and subsurface scattering should be further investigated. The Leica Scanstation C10 is the only commercial instrument with a wavelength of $532 \mathrm{~nm}$, but it is no longer on the market.

\section{ACKNOWLEDGEMENTS}

The research has been financially supported by the non-profit foundation "Friends of Florence" (www.friendsofflorence.org) that is gratefully acknowledged. Authors also thank arch. Gaetano d'Agnelli and Gianni Abate for their collaboration and loaning their laser scanners and Valentina Bonora and Adele Meucci for the design and measurement of the topographic network.

\section{REFERENCES}

Adamopoulos, E., Rinaudo, F., Ardissono, L., 2021 A Critical Comparison of 3D Digitization Techniques for Heritage Objects. ISPRS Int. J. Geo-Inf. 10, 10. doi.org/10.3390/ijgi10010010

Angheluţă, L.M., Rădvan, R. 2020.3D digitization of translucid materials in cultural heritage objects: a comparative study between laser scanning and photogrammetry. Romanian Journal of Physics. 65, 906.

Aldrovandi, A., Balzani, M., Cagnini, A., Censini, G., De Luca, D., Fratini, F., Garzonio, C.A., Giamello, M., Hoyte, J., Improta, M.C., Mugnaini, S., Porcinai, S., Scala A. and Sorella, F., 2011. La campagna diagnostica sul pulpito di Giovanni Pisano nella chiesa di Sant'Andrea a Pistoia: una necessaria premessa al restauro conservativo. OPD RESTAURO 23, 221252.
Bartoli, G., Betti, M., Bonora, V., Conti, A., Fiorini, L., Kovacevic, V., Tesi, V. and Tucci, G., 2020. From TLS data to FE model: a workflow for studying the dynamic behavior of the Pulpit by Giovanni Pisano in Pistoia (Italy). Procedia Structural Integrity. 29. 55-62. doi.org/10.1016/j.prostr.2020.11.139.

Bonora, V., Tucci, G., Meucci, A., Pagnini, B., 2021 a. Photogrammetry and 3D Printing for Marble Statues Replicas: Critical Issues and Assessment. Sustainability, 13(2), 680.

Bonora, V., Maseroli, R., Mugnai, F., Tucci, G., 2021b. GNNS Control Network Supporting Large Historical Building Architectural Survey. Int. Arch. Photogramm. Remote Sens. Spatial Inf. Sci. 46 87-91. doi.org/10.5194/isprs-archives-XLVIM-1-2021-87-2021

Callieri, M., Cignoni, P., Dellepiane, M., Scopigno, R., 2009. Pushing time-of-flight scanners to the limit, 10th International Symposium on Virtual Reality, Archaeology and Intelligent Cultural Heritage (VAST 09), St. Julians, Malta. doi.org/10.2312/VAST/VAST09/085-092

Carli, E., 1986. Giovanni Pisano. Il pulpito di Pistoia. Milano, Giorgio Mondadori Ed. EAN:2560028468315

Cloud Compare development team, 2022. Cloud Compare. GPL software. https://www.danielgm.net/cc/

Dent, P., 2008. "Laude Dei Trini": Observations Towards a Reconstruction of Giovanni Pisano's Pistoia Pulpit. Journal of the Warburg and Courtauld Institutes, 71, 121-138. www.jstor.org/stable/20462779

El-Hakim, S., Beraldin, J.-A., Picard, M., Cournoyer, L. 2008. Surface Reconstruction of Large Complex Structures from Mixed Range Data - The Erechtheion Experience. Int. Arch. Photogramm. Remote Sens. Spatial Inf. Sci. 37 1077-1082.

Fazio, L., Lo Brutto, M. (2021). An experimental workflow for the virtual reconstruction of ancient statues. Proceedings of the ARQUEOLÓGICA 2.0 - 9th International Congress \& 3rd GEORES - GEOmatics and pREServation Digital Twins for Advanced Cultural Heritage Semantic Digitization Valencia: Editorial Universitat Politècnica de València 542-545. doi.org/10.4995/arqueologica9.2021.13259

Garcia-Fernandez, J. 2016. An Assessment of Errors and Their Reduction in Terrestrial Laser Scanner Measurements in Marmorean Surfaces. $3 D$ Research 7, 2. doi.org/10.1007/s13319-015-0077-0

Georgopoulos A., Stathopoulou E.K., 2017. Data Acquisition for 3D Geometric Recording: State of the Art and Recent Innovations. In: Vincent M., López-Menchero Bendicho V., Ioannides M., Levy T. (eds) Heritage and Archaeology in the Digital Age. Quantitative Methods in the Humanities and Social Sciences. Springer, Cham. doi.org/10.1007/978-3-319-6537091 
Gnudi, G., 1972. Il pulpito di Giovanni Pisano a Pistoia, In: Il Gotico a Pistoia nei suoi rapporti con l'arte gotica italiana. Atti del $2^{\circ}$ Convegno internazionale di studi, Pistoia 1966, Roma pp. 165-179

Godin, G., Rioux, M., Beraldin, J., Levoy, M., Cournoyer, L., \& Blais, F., 2001. An assessment of laser range measurement on marble surfaces. Proc. $5^{\text {th }}$ Conf. on Optical $3 D$ measurement techniques, Vienna, 49-56 NRC 44210. NRC-CNRC

Guidi, G., Remondino, F., Russo, M., Spinetti, A., 2009. Range sensors on marble surfaces: quantitative evaluation of artifacts, Proc. SPIE 7447, Videometrics, Range Imaging, and Applications X, 744703. doi.org/10.1117/12.827251

Huerto-Cardenas, H.E., Aste, N., Del Pero, C.; Della Torre, S.; Leonforte, F., 2021 Effects of Climate Change on the Future of Heritage Buildings: Case Study and Applied Methodology. Climate 9 132. doi.org/10.3390/cli9080132

Jászai, G., 1968. Die Pisaner Domkanzel. Neuer Versuch zur Wiederherstellung ihres ursprünglichen Zustandes, München, Dabnubia

Lague, D., Brodu, N., Leroux, J. 2013. Accurate 3D comparison of complex topography with terrestrial laser scanner: Application to the Rangitikei canyon (NZ). ISPRS journal of photogrammetry and remote sensing, 82, 10-26. doi.org/10.1016/j.isprsjprs.2013.04.009

Luhmann, T., Robson, S., Kyle, S., and Boehm, J. 2019. CloseRange Photogrammetry and $3 D$ Imaging, Berlin, Boston: De Gruyter. doi.org/10.1515/9783110607253

Malik, U.S., Guidi, G., 2018. Massive 3D digitization of sculptures: Methodological approaches for improving efficiency. IOP Conf. Ser.: Mater. Sci. Eng. 364012015 doi:10.1088/1757-899X/364/1/012015

Mellini, G.L., 1969. Il pulpito di Giovanni Pisano a Pistoia, Milano, Electa

Moyano, J.; Nieto-Julián, J.E.; Bienvenido-Huertas, D.; MarínGarcía, D., 2020. Validation of close-range photogrammetry for architectural and archaeological heritage: Analysis of point density and 3d mesh geometry. Remote Sens., 12, 3571

Nicolae, C., Nocerino, E., Menna, F., and Remondino, F.: 2014 Photogrammetry applied to Problematic artefacts, Int. Arch. Photogramm. Remote Sens. Spatial Inf. Sci., XL-5, 451-456, doi.org/10.5194/isprsarchives-XL-5-451-2014.

Remondino, F., 2011. Heritage recording and 3D modeling with photogrammetry and 3D scanning. Remote sensing 3.6 11041138. doi.org/10.3390/rs3061104

Ruiz, R. M., Torres, M. T. M., \& Allegue, P. S., 2021 Comparative Analysis Between the Main 3D Scanning Techniques: Photogrammetry, Terrestrial Laser Scanner, and
Structured Light Scanner in Religious Imagery: The Case of The Holy Christ of the Blood. ACM Journal on Computing and Cultural Heritage, 15(1), 1-23

Santos, P., Ritz, M., Fuhrmann, C., Fellner, D., 2017. 3D mass digitization: a milestone for archeological documentation. $\begin{array}{llll}\text { Virtual Archaeology Review } & 8.16 & 1-11 .\end{array}$ doi.org/10.4995/var.2017.6321

Siedel, M., 2012. Padre e Figlio. Nicola e Giovanni Pisano. Marsilio, Venezia

Tsakiri, M., Ioannidis, C., Carty, A., 2003. Laser scanning issues for the geometrical recording of a complex statue, Proc. $6^{\text {th }}$ Conf. Optical 3-D Measurement Techniques, Zurich, Switzerland.

Tucci, G., Bonora, V., Conti, A., Fiorini, L., 2017. High-quality $3 \mathrm{~d}$ models and their use in a cultural heritage conservation project. Int. Arch. Photogramm. Remote Sens. Spatial Inf. Sci., $42,687$.

Voegtle, T., Wakaluk, S., 2009. Effects on the measurements of the terrestrial laser scanner HDS 6000 (Leica) caused by different object materials. Int. Arch. Photogramm. Remote Sens. Spatial Inf. Sci. XXXVIII-3/W8, 68-74. 